\title{
The Role of Mesoscale Eddies in the Source Regions of the Agulhas Current
}

\author{
Arne Biastoch AND WolfGang Krauss
}

Institut für Meereskunde, Kiel, Germany

(Manuscript received 5 March 1998, in final form 19 October 1998)

\begin{abstract}
A primitive equation model to study the dynamics of the Agulhas system has been developed. The model domain covers the South Atlantic and the south Indian Ocean with a resolution of $13^{\circ}$ in the Agulhas region while coarser outside. It is driven by a climatology of the European Centre for Medium-Range Weather Forecasts. It is shown that the model simulates the Agulhas Current, its retroflection, and the ring shedding successfully. The model results show baroclinic anticyclonic eddies in the Mozambique Channel and east of Madagascar, which travel toward the northern Agulhas Current. After the eddies reach the current they are advected southward with the mean flow. Due to the limited numerical resolution only a few eddies reach the retroflection region without much modification. These eddies are responsible for drastic enhancement of the heat transfer from the Indian Ocean to the South Atlantic and lead to periodicities in the interoceanic heat transport of about 50 days superimposed on the seasonal variability. Combined satellite data from TOPEX/Poseidon and ERS-1 show that the observed vortices in the Mozambique Channel are comparable to those seen in the model. In contrast to this the simulated eddies east of Madagascar seem not to be well reproduced. Analyses of the energy conversion terms between the mean flow and the eddies suggest that barotropic instability plays an important role in the generation of Mozambique Channel eddies. For the generation of Agulhas rings and other eddy structures in the model the barotropic instability mechanism seems to be minor, and baroclinic instability mechanisms are more likely.
\end{abstract}

\section{Introduction}

The region around the southern part of Africa is unique in its dynamics and features. The combination of a strong and very stable western boundary current, the Agulhas Current (Lutjeharms 1996), a region of very high mesoscale activity at its termination and the importance of small-scale features like "Natal Pulses," provide for a wide range of motions and interactions. The region also appears to play an important role in the global thermohaline circulation (Broecker 1991). As the main region of the one alternative of warm water return flow to the North Atlantic, the so-called warm water path (Gordon et al. 1992), it serves as a missing link. To understand the interoceanic transport of mass, heat, and salt a detailed knowledge of the dynamics of the Agulhas region is essential.

A number of open key questions prevent the understanding of the Agulhas region from being complete. First, the identification of the source regions of the Agulhas Current is unknown. Historical data point out that the main transport of the current is established by re-

Corresponding author address: Dr. Arne Biastoch, Dept. of Theoretical Oceanography, Institut für Meereskunde, Düsternbrooker Weg 20, 24105 Kiel, Germany.

E-mail: abiastoch@ifm.uni-kiel.de circulation in a subgyre of the southwest Indian Ocean (Stramma and Lutjeharms 1997). Contributions from the South Equatorial Current via the East Madagascar Current are also evident. Great uncertainty remains about the role of the Mozambique Channel. The sparse hydrographic observations do not give a consistent picture of the feeding of the Agulhas Current. In the time mean Stramma and Lutjeharms (1997) estimate this transport as $5 \mathrm{~Sv}\left(\mathrm{~Sv} \equiv 10^{6} \mathrm{~m}^{3} \mathrm{~s}^{-1}\right)$ or below.

After being fully developed at about $25^{\circ} \mathrm{S}$ the Agulhas Current is in general very invariant in its path (Gründlingh 1983)_although times occur when it cannot be found within its well-defined range off the coast-and seems to have only small seasonal variability (Pearce and Gründlingh 1982). Recent analysis indicates a mean volume transport of $65 \mathrm{~Sv}$ in the upper $1000 \mathrm{~m}$ (Stramma and Lutjeharms 1997). South of the African continent the current leaves the shelf, retroflects in a tight anticyclonic loop, and flows back into the Indian Ocean. At the retroflection, which occurs in general between $20^{\circ} \mathrm{E}$ and $15^{\circ} \mathrm{E}$ (Lutjeharms and van Ballegooyen 1988), warm core rings are generated by loop occlusion and drift into the South Atlantic. Even though the general mechanism of ring shedding has been described in detail (Lutjeharms and van Ballegooyen 1988), quantification of the number of rings shed per year and the amount of mass, heat, and salt transported are only roughly 


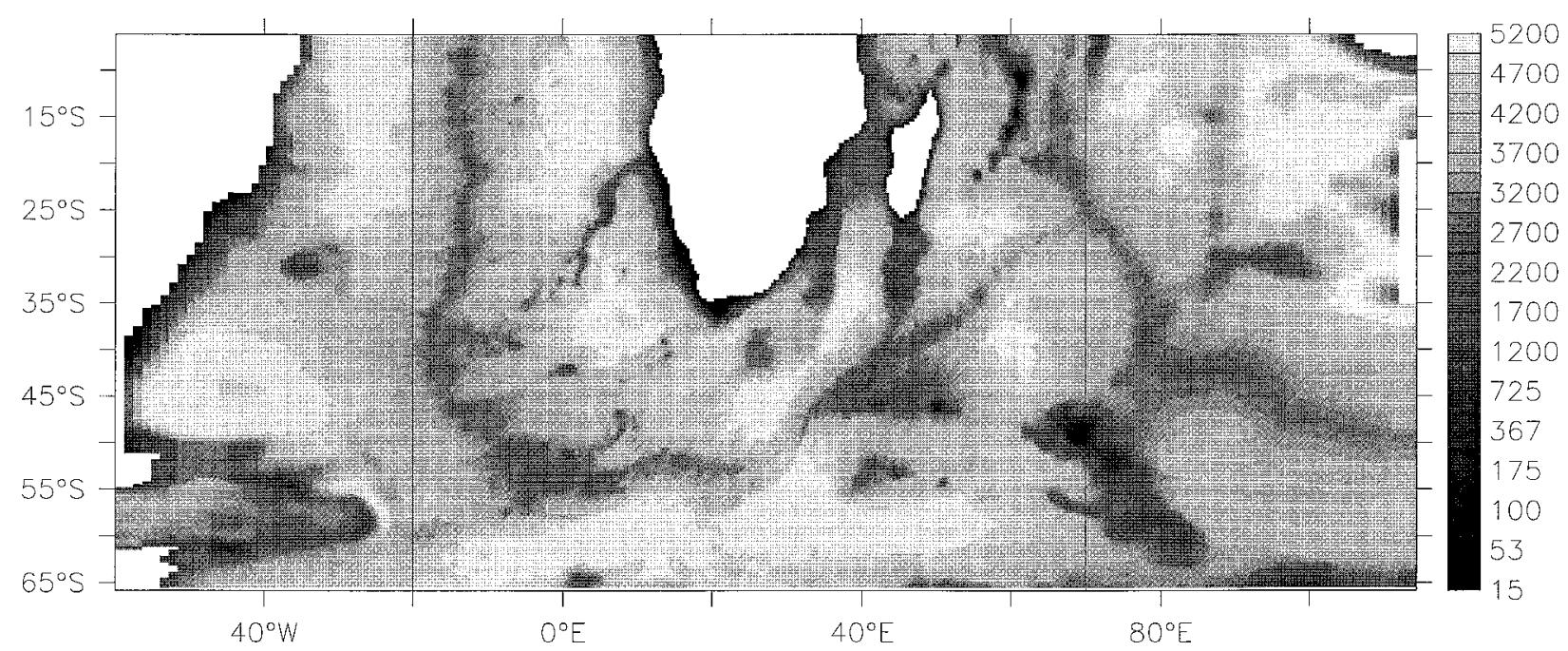

FIG. 1. Model topography. Boxes indicate horizontal resolution, the vertical axis is shown by the grayscale key. Note the constant resolution in the region of interest $\left(20^{\circ} \mathrm{W}-70^{\circ} \mathrm{E}\right)$ and the smooth coarsing in longitudinal direction outside. Open boundary conditions are specified at the water points of all western, eastern, and northern walls.

known. For example, estimates of the westward heat transfer from the Indian to the Atlantic Ocean due to Agulhas rings currently range from $1.0 \times 10^{-3} \mathrm{PW}$ (Garzoli et al. 1996) to $7.5 \times 10^{-3} \mathrm{PW}$ (van Ballegooyen et al. 1994) $\left(1 \mathrm{PW}=10^{15} \mathrm{~W}\right)$.

For investigating these links in the global circulation it is necessary to understand the mesoscale circulation around the southern part of Africa and at least the Agulhas Current itself in a proper manner. Numerical modeling can help here because of the possibility of a dynamically consistent picture and the feasibility of changing single parameters to point out their relative importance and consequences. There are existing models that cover the Agulhas region but these are either global (Thompson et al. 1997; McClean et al. 1997; Maltrud et al. 1998) and therefore not practical for running sensitivity studies, required for separating single problems, or are not eddy resolving (Matano 1996).

An eddy-resolving model of the Agulhas region has therefore been developed to study the dynamics of the Agulhas Current and the interoceanic exchange south of Africa (Biastoch 1998). This model is described in the next section. Section 3 deals with some general results to verify the numerical experiments, after that a description of the most obvious feature of the model, the mesoscale eddies in the source regions of the Agulhas Current, is given (section 4). A discussion where the occurrence in the real ocean should be verified and a summary (section 5) closes the paper.

\section{Model and data}

The model that is used here is the Modular Ocean Model (MOM: Pacanowski 1996), a flexible and widely used version of the Geophysical Fluid Dynamics Laboratory Model described by Bryan (1969) and devel- oped by Cox (1984). It is based on the set of primitive equations where the horizontal components of velocity and the tracers, temperature and salinity, are prognostically integrated, the vertical component of velocity is diagnosed via the continuity equation. After splitting of the horizontal velocity components into a baroclinic and a barotropic mode the application of a rigid-lid approximation allows a streamfunction to be introduced.

The model covers the South Atlantic and the Indian Ocean from $6.5^{\circ} \mathrm{S}$ to $65^{\circ} \mathrm{S}, 60^{\circ} \mathrm{W}$ to $115^{\circ} \mathrm{E}$ (Fig. 1). The horizontal resolution is $1 / 3^{\circ} \times 13^{\circ}$ in the region of interest $\left(20^{\circ} \mathrm{W}-70^{\circ} \mathrm{E}\right)$, in the longitudinal direction the grid becomes coarser following a sinusoidal function to $\lambda=$ $1.2^{\circ}$ at the meridional boundaries. In the vertical the water column is resolved by 29 levels with $\Delta z$ varying between 15 and $250 \mathrm{~m}$. In Fig. 1 the increasing boxes from the fine resolution area toward the boundaries indicate directly the smooth transition to the coarse resolution area, the vertical resolution is shown by the grayscale key. This grid is a compromise for computational costs between a fine resolution in the Agulhas region that is required to simulate the Agulhas rings and a model domain large enough to be bounded by several landmasses. Nevertheless open boundaries enclose the model-the Atlantic and Indian Ocean to the north, Drake Passage to the west, and the Indonesian Throughflow and the Southern Ocean south of Australia to the east-where the model has to be connected to the rest of the World Ocean. The simplest way of doing this would be to restore temperatures and salinity to climatological or observed values in these zones. But in this case reflections at these boundaries could occur and disturb the solution of the whole model.

A better option is to implement open boundary conditions to allow waves and disturbances to propagate outward. Here open boundary conditions according to 
Stevens (1990) are used, which means that the baroclinic velocities are calculated at the open boundaries using the linearized horizontal momentum equations. Thus, the vertical shear of the current is free to adjust local density gradients. Heat and salt are transported out of the domain using a radiation condition plus advection if the normal component of the velocity at the boundary is directed outward. At the points where the normal component is directed inward, a restoring to prescribed data takes place-in this case to the monthly climatology of Levitus et al. (1994) and Levitus and Boyer (1994). To give the model information about the barotropic circulation outside the domain the streamfunction is prescribed from the Parallel Ocean Climate Model (POCM) - known as the Semtner and Chervin Model (Semtner and Chervin 1992). Here a run with similar forcing data (Stammer et al. 1996, their run POCM 4A) has been chosen to also provide a monthly climatology.

The bottom topography is based on the NGDC 5 arcminute dataset and smoothed by a two-dimensional symmetric filter (Shapiro 1970) once in the fine-resolution region and three times in the rest of the model domain. After the smoothing attempt (which is necessary to avoid topographic instabilities), we have focused on the realistic representation of single topographic features. As an example it has been speculated that the wrong position of the Agulhas retroflection in the Fine Resolution Antarctic Model (FRAM: FRAM Group 1991) would be a result of the strong smoothing of the channel between the African continent and the Agulhas Bank (Lutjeharms and Webb 1995). In level models with a no-slip boundary condition like MOM advection of water is only possible if at least two ocean boxes appear in the desired depth. To ensure the exact representation of the key topographic features (e.g., Agulhas Plateau, Walvis Ridge, or Mozambique Channel; see Thompson 1995) these are rebuilt to their original depth or widened to allow advection of water through these gaps.

Horizontal subgrid-scale diffusion and viscosity are parameterized using a biharmonic operator with coefficients $A_{h}=A_{m}=-2.5 \times 10^{19} \mathrm{~cm}^{4} \mathrm{~s}^{-1}$. Because of the strong dependence of the numerical stability on the biharmonic coefficients these are fixed for the $1 / 3^{\circ} \times 1 / 3^{\circ}$ region and scaled by $(\Delta \lambda)^{3}$ in the rest of the domain. In the vertical a constant Laplacian parameterization is used $\left(k_{h}=0.3 \mathrm{~cm}^{2} \mathrm{~s}^{-1}, k_{m}=5.0 \mathrm{~cm}^{2} \mathrm{~s}^{-1}\right)$.

At the ocean surface a thermal parameterization after Haney (1971) is provided where the topmost level is restored to an apparent atmospheric temperature using a variable restoring scale with coefficients after Han (1984) to take into account the feedback of the ocean on the forcing; shortwave radiation is included as a direct penetrative insolation. Together with the wind values all data are taken from a consistent monthly climatology (Barnier et al. 1995), an analysis of the weather forecast model of the European Centre for MediumRange Weather Forecasts (ECMWF). The cube of the friction velocity $\left(u^{* 3}\right)$ is used to force a simple mixed layer model of the Kraus-Turner type [Kraus and Turner (1967); wind-driven part only). The surface salinity is restored with a timescale of 50 days to the climatology of Levitus et al. (1994). To ensure the representation of the Antarctic Bottom Water in the model, a zone of $4^{\circ}$ latitude has been specified in the vicinity of the Weddell Sea where the tracers in the whole water column are restored to the initialization data (see below). To avoid unrealistic cold temperatures a "zero order" ice model has been included, which simply means that the sea surface fluxes that would cool the water are cut off at points where the sea surface temperature is below a certain value $\left(-1.8^{\circ} \mathrm{C}\right)$.

The model is initialized with potential temperatures and salinities from the Levitus WOA94 dataset (Levitus et al. 1994; Levitus and Boyer 1994) and started from rest. It has been run for 30 model years to spin up to a quasi-stationary state, which means that the wind-driven circulation is stationary with a seasonal cycle. The thermohaline circulation is varying on a timescale of thousands of years, which is too expensive to integrate. So the fields of temperature and salinity have a slow drift, but nevertheless provide a good representation of the general circulation. After this spinup period the threedimensional model fields have been sampled with an interval of 3 days to produce a monthly climatology over a time range of 5 years.

For comparison satellite data have been used. These are combined data from the European Remote Sensing Satellite No. 1 (ERS-1) and TOPEX/Poseidon (TP) of the period October 1992-December 1993, where the ERS -1 orbits are fitted to TP using a global minimization of dual crossover differences (Le Traon et al. 1995; Le Traon and Ogor 1998). This consistent dataset combines the higher spatial resolution of the $E R S-1$ data with the better accuracy of TP. The rms error is $2 \mathrm{~cm}$ (AVISO 1998). The sea level anomalies that are obtained by subtracting a 3-yr mean have been interpolated on the model grid using a linear objective analysis technique in space and time (Bretherton et al. 1976), which produced a 5-day time series of quasi-synoptic maps (A. Köhl and N. Rix, personal communication).

\section{General model results}

A snapshot of the fine-resolution region (up to $55^{\circ} \mathrm{S}$ ) at 436-m depth (Fig. 2) shows the narrow Agulhas Current with maximum velocities of $85 \mathrm{~cm} \mathrm{~s}^{-1}$ close to the African shelf (at the surface velocities of more than 2 $\mathrm{m} \mathrm{s}^{-1}$ occur). At this depth it is fed directly by the East Madagascar Current, whereby anticyclonic eddies dominate this contribution. The Agulhas Current retroflects at $15^{\circ} \mathrm{E}$ and flows back to the Indian Ocean along a strong meandering temperature front. The latter flow is in good agreement with the Agulhas Return Current prescribed by Lutjeharms and Ansorge (1997), manuscript submitted to J. Phys. Oceanogr.; hereafter LA97).

In the direct vicinity of the Agulhas retroflection a 


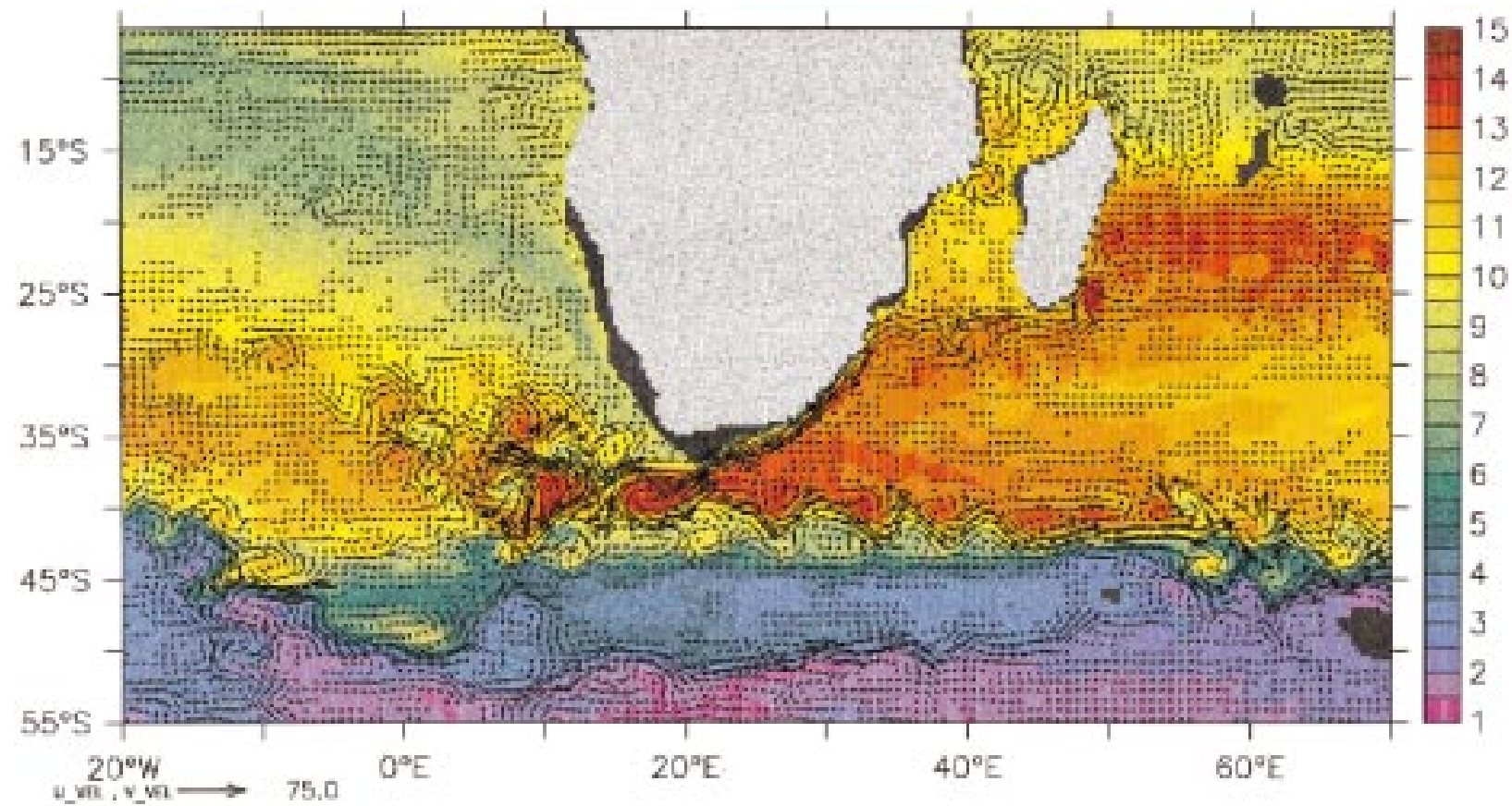

FIG. 2. Snapshot of potential temperature and velocity at 436-m depth (level 10) for model day 18 Mar 35 (for velocity vectors every second grid point is shown, values less than $2 \mathrm{~cm} \mathrm{~s}^{-1}$ are omitted). Land is shown in light gray and topography in dark gray.

complicated formation and drift of vortices occurs. Warm core rings are spawned and drift along a northwesterly route into the South Atlantic. About four to six rings per year of different sizes and intensities can leave the region and cross the World Ocean Circulation Experiment section A11, a line which runs from $45^{\circ} \mathrm{S}$, $15^{\circ} \mathrm{W}$ to the African coast at $30^{\circ} \mathrm{S}$. Similar to results obtained from satellite observations (Gordon and Haxby 1990; Byrne et a1. 1995) the path of the ring drift is not invariant but spreads out over a broader latitudinal range, indicating two main pathways.

The distance between the maxima of radial velocity is a commonly used criterion for the diameter of Agulhas rings. Duncombe Rae (1991) examined 17 rings from historical data and found an average value of 240 $\pm 40 \mathrm{~km}$. With diameters between 220 and $300 \mathrm{~km}$ the three anticyclonic rings $\left(34^{\circ} \mathrm{S}, 8^{\circ} \mathrm{E} ; 33^{\circ} \mathrm{S}, 1^{\circ} \mathrm{W}\right.$; and $29^{\circ} \mathrm{S}$, $\left.9^{\circ} \mathrm{W}\right)$ in this snapshot fit more or less into this range. Duncombe Rae (1991) noted also an average depth of the $10^{\circ} \mathrm{C}$ isotherm of $650 \pm 130 \mathrm{~m}$ in the center of the Agulhas rings, which is in good agreement with values of 600-700 m here (not shown). Cold core, cyclonic eddies are also generated at the Agulhas retroflection, which with anticyclonic ones initially appear as dipoles, but the cyclonic eddies have shorter lifetimes and remain in the vicinity of the retroflection. This dipolelike behavior, with more intensity in the anticyclonic than in the cyclonic part, has also been observed by satellite measurements (Gründlingh 1995). The cyclonic parts are acting as a recoil effect (Flierl 1977).

Figure 3 shows the mean volume transport of the model. Between $30^{\circ}$ and $35^{\circ} \mathrm{S}$ the transport of the Agulhas Current increases from 47 to $67 \mathrm{~Sv}$. Stramma and Lutjeharms (1997) got a maximum transport of the Agulhas Current of $65 \mathrm{~Sv}$ in the upper $1000 \mathrm{~m}$ from the historical data, which agrees well with the value of this model. A comparison of the model transport with the Sverdrup transport calculated from the wind data alone shows an excess toward the south, which points out the degree of nonlinearity in the system. At $35^{\circ} \mathrm{S}$ the mean transport in the model is more than $10 \mathrm{~Sv}$ higher than the linear Sverdrup solution.

The splitting of the current into three sources fits also well with the observations: about $5 \mathrm{~Sv}$ flows through the Mozambique Channel, $20 \mathrm{~Sv}$ from east of Madagascar, and the rest by its own recirculation in the subtropical gyre of the Indian Ocean. It is noteworthy that the transport through the Mozambique Channel has a seasonal cycle. During the northeast monsoon phase in austral summer the buffer zone of low winds that divides the west winds along the equator from the southeast trades in the subtropics has shifted southward and cuts off the channel from the anticyclonic subtropical circulation. In consequence the transport through Mozambique Channel is zero or very low (Fig. 4). In contrast the transport is high with values up to $22 \mathrm{~Sv}$ in the high phase of the southwest monsoon. This is a combined effect of the northward-shifted trades together with the occurrence of a maximum in the wind stress at the northern tip of Madagascar (Biastoch et al. 1999, manuscript submitted to Geophys. Res. Lett.). The latter provides an additional Ekman transport that is directed into the 


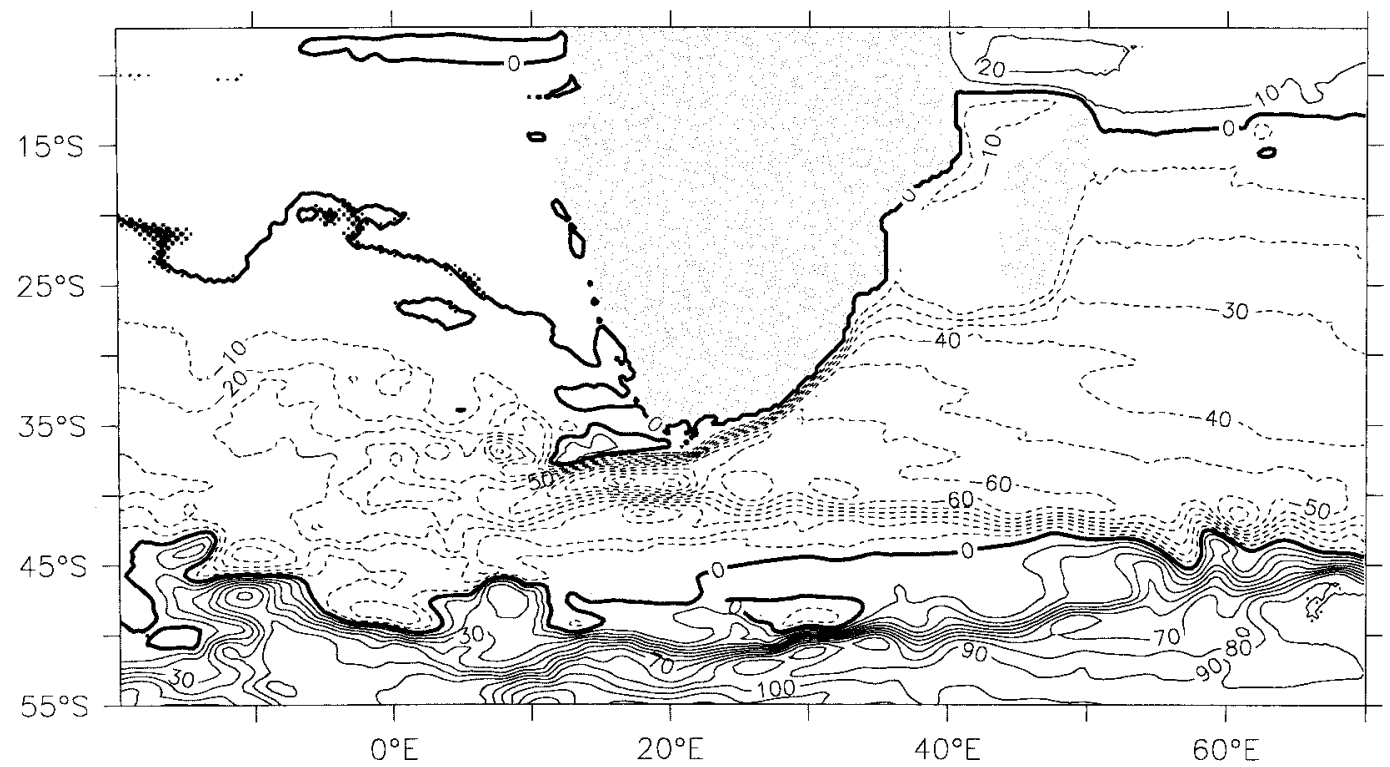

FIG. 3. Mean barotropic streamfunction, averaged over the last five model years (30-35), in Sv. Negative values indicate anticyclonic circulation.

channel. In this time the flow through the Mozambique Channel contributes a quarter of the Agulhas Current transport and is not neglectible.

A main difference between the model and observations is the degree of recirculation of the Agulhas Return Current. Where Stramma and Lutjeharms (1997) calculated a recirculation of $20 \mathrm{~Sv}$ west of $50^{\circ} \mathrm{E}$ and a further $20 \mathrm{~Sv}$ up to $70^{\circ} \mathrm{E}$, this is halved in the model (Fig. 3). It can be shown that this is a result of the high barotropic transport of the Antarctic Circumpolar Current (ACC), which is maintained by values around 185 Sv in Drake Passage and south of Australia. These, obtained from POCM (Stammer et al. 1996), are too high in comparison to observations. The consequence is a later recirculation of the Agulhas Return Current in the

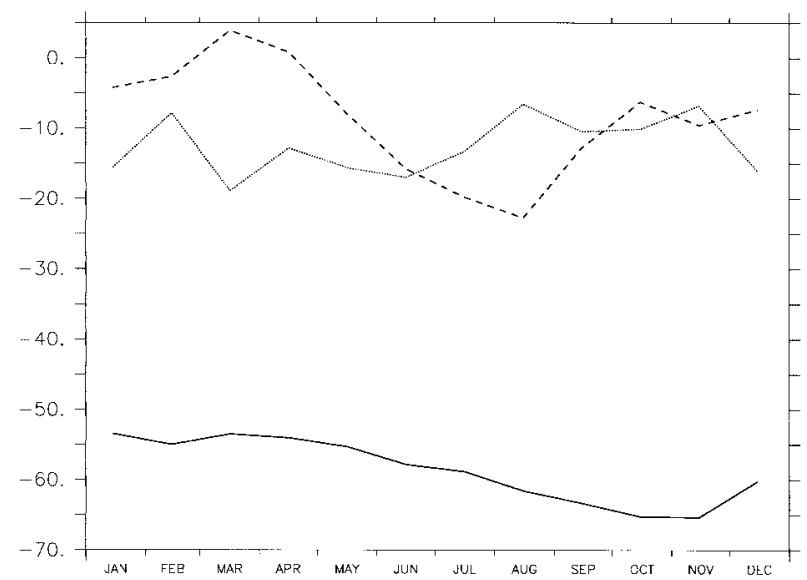

FIG. 4. Mean volume transports of the Agulhas Current at $32^{\circ} \mathrm{S}$ (solid line), through the Mozambique Channel at $23^{\circ} \mathrm{S}$ (dashed line), and of the East Madagascar Current at $23^{\circ} \mathrm{S}$ (dotted line) in Sv. subtropical gyre due to the strong advection by the neighboring ACC.

Obvious in Fig. 3 is the clear interconnection between the Indian and the Atlantic Ocean, a consequence of the zero line of the wind stress curl located $10^{\circ}-15^{\circ}$ south of the southern tip of Africa. More than $30 \mathrm{~Sv}$ reaching far-up to $2500 \mathrm{~km}$-into the Atlantic, $20 \mathrm{~Sv}$ of this contributes directly to the subtropical gyre. Since the Indian Ocean is warmer at the same latitude than the Atlantic this results in an interoceanic transfer of heat. Thompson et al. (1997) obtained the zonal heat transport due to the Agulhas Current system in FRAM by integrating from the African continent to the zero line of the streamfunction $\psi$ [Eq. (1)]:

$$
a \rho C_{p} \int_{H}^{0} \int_{\text {Africa }}^{\psi=0} \overline{u \theta} d \phi d z,
$$

where $a$ is radius of the earth, $\rho$ potential density, $C_{p}$ heat capacity, $u$ zonal velocity, and $\theta$ potential temperature; $\overline{u \theta}$ means that the product of both quantities is averaged in time (in our case over 5 model years). At $20^{\circ} \mathrm{E}$ (and approximately $48^{\circ} \mathrm{S}$ ) we end up with a value of $0.87 \mathrm{PW}$ in the mean. This is relatively high compared to other modeling studies, for example FRAM with 0.51 PW (Thompson et al. 1997). Reasons for this contrast could be the different wind data, the different prescription of the thermohaline fluxes (restoring to sea surface temperatures in FRAM and a parameterization of climatological fluxes in our model), or the too small advection of warm water in the Indian Ocean in FRAM as a consequence of the closed Indonesian Throughflow (Ribbe and Tomczak 1997). Estimates from hydrography are also lower, Gordon (1985), for example, got 

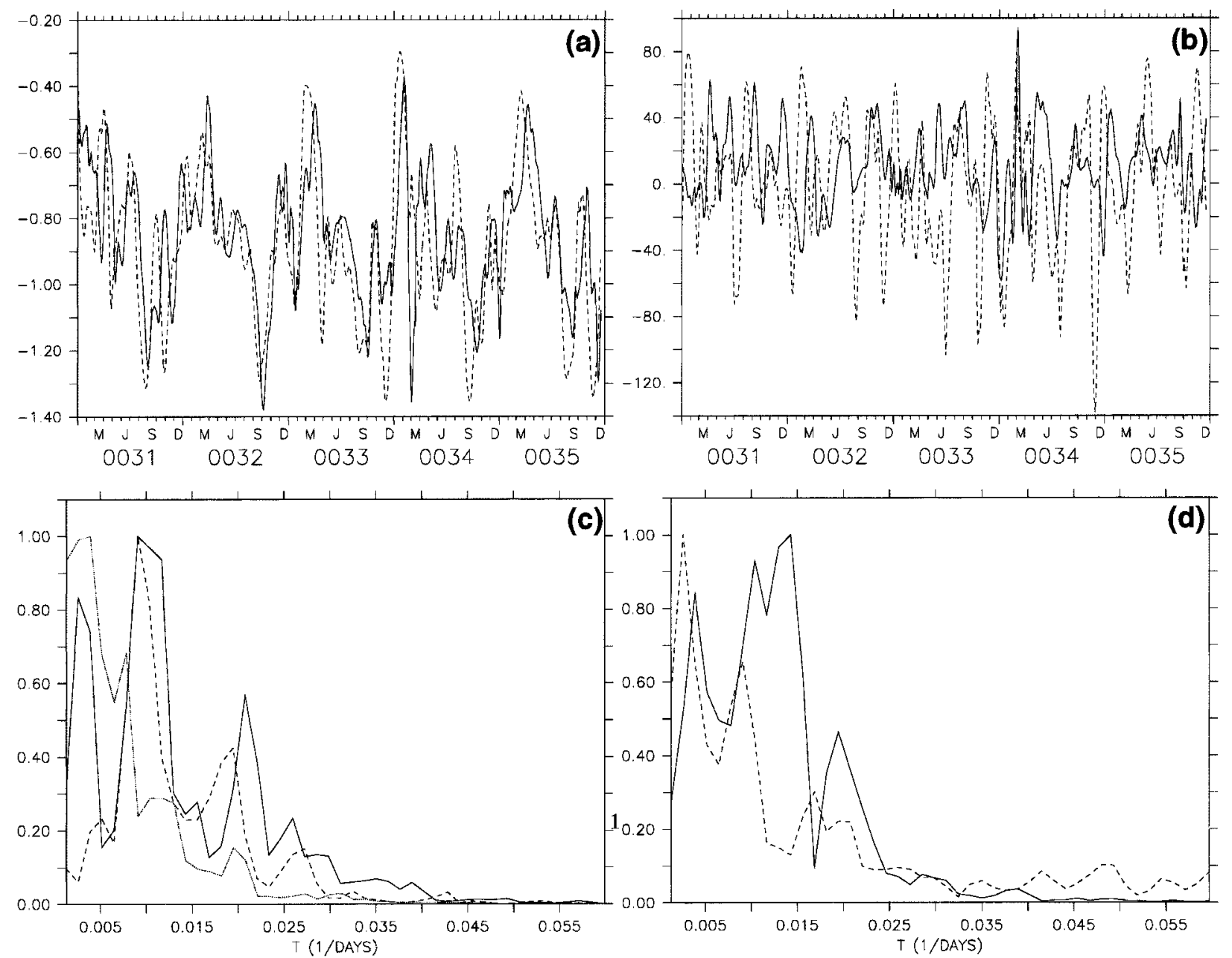

FIG. 5. (a) Integrated heat transport over the last five model years between the African continent and the zero line of streamfunction at $20^{\circ} \mathrm{E}$ (solid) and $14^{\circ} \mathrm{E}$ (dashed). Units are PW $\left(1 \mathrm{PW}=10^{15} \mathrm{~W}\right)$, negative values indicate westward transports. (b) As in (a) but for integrated vorticity $0-250 \mathrm{~m}$. Units are $10^{9} \mathrm{~m}^{2} \mathrm{~s}^{-1}$; negative values indicate anticyclonic vorticity. (c) Power spectrum of (b), normed to unit values: vorticity at $20^{\circ} \mathrm{E}$ (solid), $14^{\circ} \mathrm{E}$ (dashed), and across section A11 (dotted). (d) As in (c) but integrated over the Mozambique Channel at $18^{\circ} \mathrm{S}$, 0-250 m (solid) and over the Agulhas Current at $32^{\circ} \mathrm{S}, 0-1000 \mathrm{~m}$ (dashed).

0.023-0.47 PW from thermocline analyses, whereby the large range of values is due to the uncertainty in the return flow of cold water into the Indian Ocean. A more extensive list of estimates can be found in De Ruijter et al. (1999a).

More important than the absolute magnitude of the interoceanic heat transport is its high variability in time; Fig. 5a shows a time series over the last five model years. Because of seasonal changes in the surface boundary conditions there is a tendency of low westward heat transfer in spring and high transfer in fallbut sudden changes can occur at any time. Some of these abrupt changes do not occur at $14^{\circ} \mathrm{E}$, which means that the differences in the two time series are due to the longitudinal movement of the Agulhas retroflection zone itself. The rest of the variability might be interpreted as an indicator of the Agulhas rings generated at the retroflection zone.
More insight in the variability can be obtained from the integrated relative vorticity (Fig. 5b); here seasonal effects are smaller and the high-frequency structure is more evident. The uncorrelated amplitudes mirror the complicated structure in the retroflection zone with both anticyclonic and cyclonic vortices. A power spectrum of the curves (Fig. 5c) shows that the predominant periods are the same, with maxima at 110 and around 50 days. There is no annual period in the vorticity at $14^{\circ} \mathrm{E}$, which provides that the retroflection zone itself has a seasonal cycle in moving back and forth in longitudinal direction. The occurrence of a 50-day period in the integrated vorticity across the WOCE section A11 indicates that this is due to the Agulhas rings. To determine whether the periods of around 100 days and 50 days are due to the dynamics of the Agulhas retroflection mechanism itself or are dominated by other phenomena, we focus on two sections farther north, one across the 
Agulhas Current at $32^{\circ} \mathrm{S}$ and one in the Mozambique Channel at $18^{\circ} \mathrm{S}$. The power spectra of the integrated vorticity in the channel (Fig. 5d) has-besides the annual period-maxima in the range 70-90 days and at 51 days, those across the Agulhas Current 110 and 59 days. It seems possible that the periodicities associated with the retroflection and ring shedding are initiated in these lower-latitude regions. Further focus must therefore be given to the regions north of the Agulhas Current.

\section{Mesoscale eddies in the source regions of the Agulhas Current}

Snapshots at 41-m depth (Fig. 6) show that there are eddies not only in the vicinity of the Agulhas retroflection area but also in the Mozambique Channel and eastsoutheast of Madagascar. These are of smaller size than the Agulhas rings but partly have more radial velocities than the Agulhas rings. The South Equatorial Current (SEC), which separates the monsoonal circulation in the northern Indian Ocean from the subtropical regime in the south (Gordon et al. 1997), flows westward at $12^{\circ} \mathrm{S}$ and splits into two parts at the northern tip of Madagascar. The northern branch flows toward the East African coast and again divides into a northward flowing East African Coastal Current, which leaves the model domain, and an anticyclonic loop in the northern Mozambique Channel. This loop pinches off anticyclonic eddies that travel southward with the mean current through the channel. An example of such an eddy is marked in Fig. 6.

Because of the beta effect the eddies are trapped at the coast (Bowman 1985). The drift of the eddies southward through the Mozambique Channel seems to be established mainly by advection in the Mozambique Current, which flows close to the coast with average velocities in the upper $500 \mathrm{~m}$ of $20-30 \mathrm{~cm} \mathrm{~s}^{-1}$. Also possible is a self-induced motion that results from northward and southward directed forces: After Shi and Nof (1994) an anticyclonic eddy along a wall is affected by an equatorward directed force due to the beta effect. This is compensated by a poleward effect that results from the mirror image of the eddy on the boundary. Also poleward directed is the "rocket" effect, generated by the loss of anticyclonic fluid, as a jet along the coast (Nof 1988). The sum of these three forces is usually directed poleward (Shi and Nof 1994), as in the model.

The second branch of the SEC flows southward along the eastern coast of Madagascar and forms also anticyclonic rings that pass the southern tip of the landmass and flow westward. Both kinds of vortices converge at about $27^{\circ} \mathrm{S}$ - just at the region where the Agulhas Current begins to form. They become advected southward by the Agulhas Current with speeds around $30 \mathrm{~km}$ day $^{-1}$.

These mesoscale features are seen in the mean eddy kinetic energy (EKE) (Fig. 7), as maxima in the northern and central parts of the Mozambique Channel and along the southeastern coast of Madagascar-with greater values than in the Agulhas retroflection area. Bands of relatively high values connecting these areas to the northern Agulhas Current indicate the pathways of the energetic eddies, which have been seen in the snapshots.

Another measure of the variability can be obtained from the sea surface height calculated diagnostically by the model. Figure 8 a shows the rms of the sea surface anomalies $\left(\overline{\mathrm{SSH}}^{\prime 2}{ }^{1 / 2}\right)$ of model year 31 . For this parameter the retroflection zone south of Africa does show more variability than the source regions of the Agulhas Current. Since the sea surface height is calculated diagnostically from the barotropic streamfunction, this indicates a more baroclinic signal focused at the surface for the northern eddies. A direct comparison of the two features (here not shown) offers that the Agulhas rings reach a depth down to 1500-2000 $\mathrm{m}$, whereby those in the Mozambique Channel are not deeper than $400 \mathrm{~m}$. But nevertheless there are still local maxima of variability in the Mozambique Channel and east of Madagascar. The same field, calculated from the TP/ERS-1 data (Fig. 8b), shows in general the same structure but with more smoothed (due to the objective interpolation) and somewhat higher values compared with the model. Only the variability in the Agulhas retroflection area is in the same range-but the structures are about $5^{\circ}$ farther east, indicating a retroflection of the Agulhas Current, which is too late in the model for this averaging period.

The two preferred routes of the Agulhas rings-one more northwesterly and one more zonally-are shown in both datasets, which is in good agreement with results of Byrne et al. (1995). The magnitude and meridional extent of the variability of the Agulhas Return Current between $25^{\circ}$ and $55^{\circ} \mathrm{E}$ are too low. Because the general characteristics of this flow agree with observations (LA97) this discrepancy could be due to a model current that is too stable. This may be a result of the bottom topography smoothing required in such level models to avoid instabilities. On the other hand, the Agulhas Plateau at $27^{\circ} \mathrm{E}$ could block variability from the region east of it. Only at $57^{\circ} \mathrm{E}$ where the southwest Indian basin begins eddies are shed to the north and to the south, resulting in a higher variability. The eddy paths in the Mozambique Channel and along the Agulhas Current are broader than in the model, but clear interconnections between the two exist. All in all, the mesoscale variability in the model seems to be correct in a qualitative sense.

The rms values in the northern Mozambique Channel are smaller, which indicates a more stable anticyclonic loop than simulated. The sharp maximum along the southeastern coast of Madagascar is not seen in the satellite observations - although a path of higher variability toward the Agulhas Current regions exists. But it seems that the generation of eddies directly off the east coast of Madagascar does not occur in the real ocean. Moreover it seems that the eddies travel along a south- 

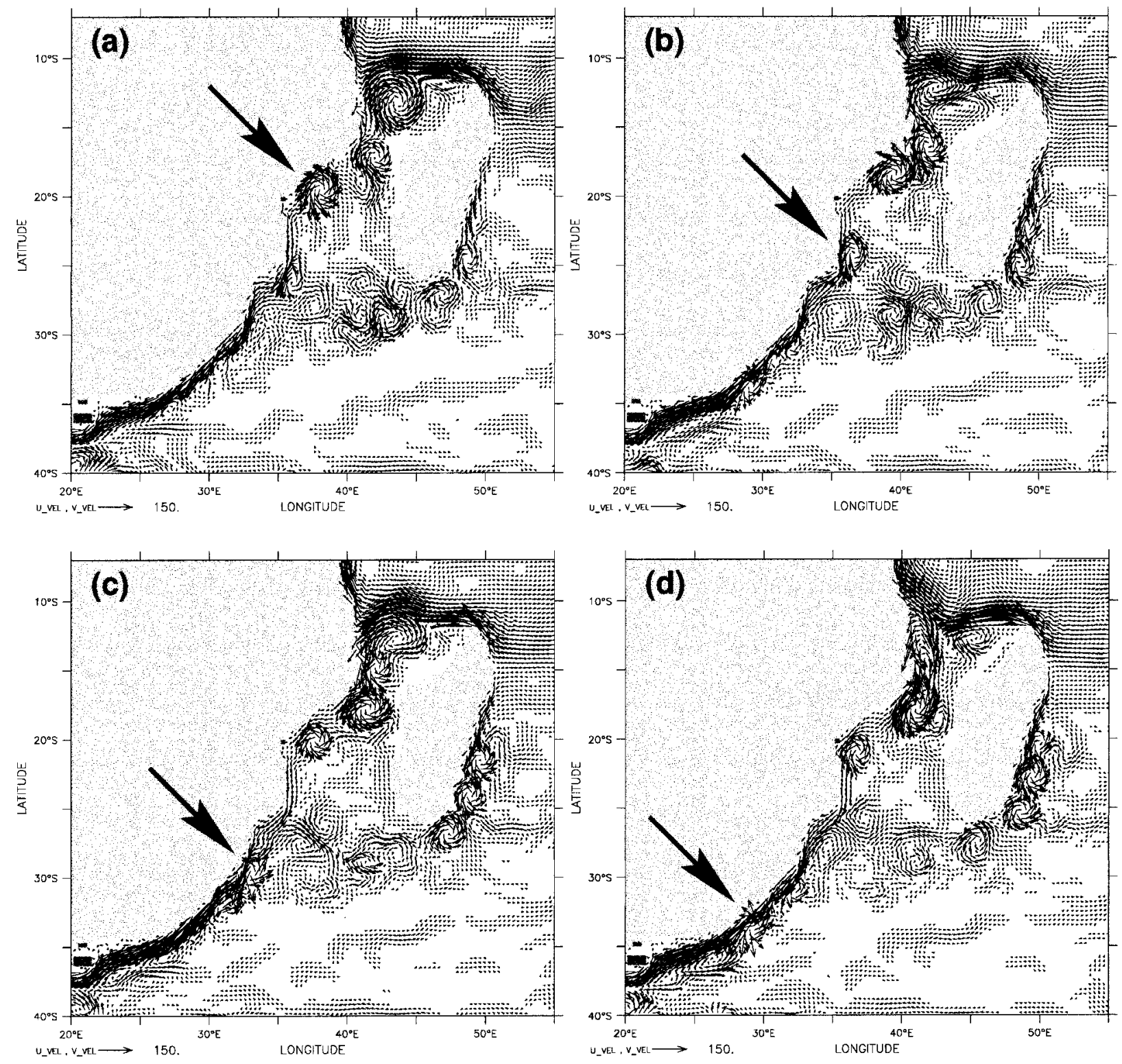

FIG. 6. Velocity vectors in 41-m depth (level 3) for model days 30 Aug 31, 20 Oct 31, 19 Nov 31, and 10 Dec 31 (values less than $5 \mathrm{~cm}$ $\mathrm{s}^{-1}$ are omitted). Note the marked eddy.

westerly route from the central Indian Ocean into the region. This is difficult to prove in the model because the resolution of the grid begins to enlarge east of $70^{\circ} \mathrm{E}$. A too zonal or slightly shifted SEC in the model could also be responsible for this lack. A key point for this seems to be the exact topographic realization of the Mascarenes Ridge at $60^{\circ} \mathrm{E}$, as Kindle (1991) showed in a simple model. The remaining analysis will therefore focus on the Mozambique Channel, which seems to be simulated in our model with more success.

Figures $9 \mathrm{a}$ and $9 \mathrm{~b}$ show latitude-time diagrams of the sea surface anomaly averaged over a strip $4^{\circ}$ wide along the African Coast from the Mozambique Channel to Port Elizabeth. Five anticyclonic vortices, indicated by pos- itive values, are found in the model within one year. The TP/ERS-1 data also show four to six anticyclonic features, but with a more complicated structure in time and space than the regular elevations in the model. A different slope indicates that the features in the satellite data travel somewhat slower than those in the model. Nevertheless, the agreement in horizontal extent and elevation values between the satellite data and the model is reasonably good. The eddies in both datasets are separated by depressions of the sea surface. It can be shown that these depressions are not due to cyclonic motions. Only small cyclonic values occur between the anticyclonic highs, which seem to act as recoil effects. Both datasets show also clearly the acceleration of the eddies 


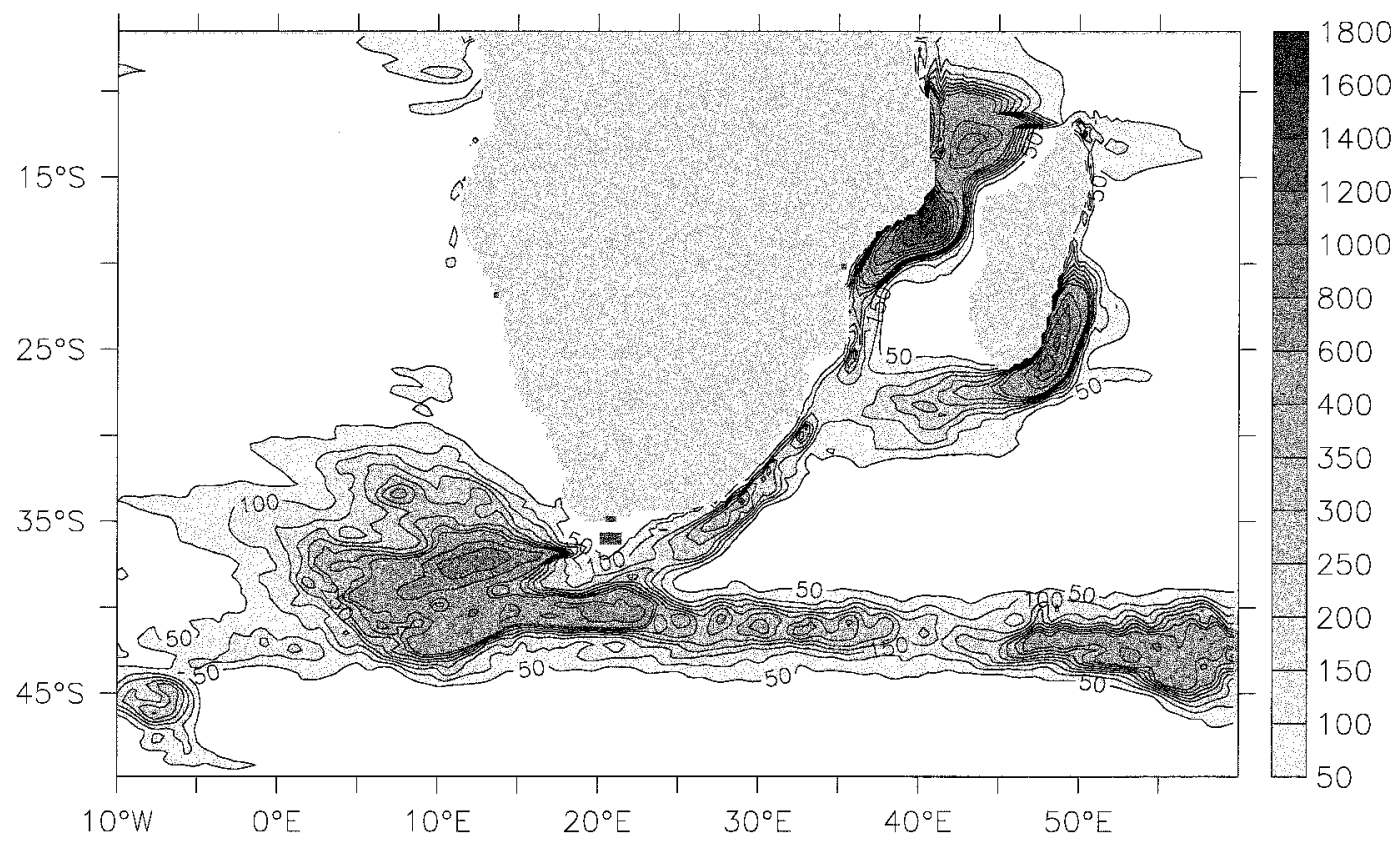

FIG. 7. Mean eddy, kinetic energy, averaged over the last five model years, at $41-\mathrm{m}$ depth. Units are $\mathrm{cm}^{2} \mathrm{~s}^{-2}$ (note the splitted key with an interval of 50 in the range 50-400 and 200 above).

south of $25^{\circ} \mathrm{S}$ by the advection in the Agulhas Current. In the model the lateral extents of the eddies south of $25^{\circ} \mathrm{S}$ show pulselike characteristics.

In the vicinity of Port Elizabeth $\left(34^{\circ} \mathrm{S}\right)$, where the current leaves the coast, most of the mesoscale eddies decay in the model (here not shown). This may have dynamical reasons, but it is most likely that numerical reasons are responsible. The first baroclinic Rossby radius decreases rapidly in this area to values below 30 $\mathrm{km}$ (Chelton et al. 1998) and is smaller than the grid size of $31 \mathrm{~km} \times 37 \mathrm{~km}$. The biharmonic operator used for diffusion and friction is very scale sensitive; it acts mainly on the smallest grid scale. So only a few eddies that are not more energetic but larger in size can pass the region and reach the Agulhas retroflection region. These have enormous influence on the dynamics in the retroflection region. For example, one eddy reaches the retroflection area by the end of February in year 34 . Due to enhancement of the velocity at the landward side of the eddy, more warm water is advected into the South Atlantic causing an increase of westward heat flux from $-0.3 \mathrm{PW}$ to $-1.35 \mathrm{PW}$ (Fig. 5a) in this time of generally low transports. But, those eddies that seem to disappear nevertheless influence the interoceanic transport. Even if these are no longer isolated vortices, enhancement of the Agulhas Current remains, which augments the transport of warm water into the South Atlantic.

To examine the mechanism responsible for the generation of the eddies in the Mozambique Channel, energy interaction terms are calculated from the 5-yr statistics of the model. The energy equation, deduced from the two horizontal velocity component $(u, v)$ equations, with all variables split into time-mean components and fluctuations, $a=\bar{a}+a^{\prime}$, contains two terms that describe the interaction between the mean flow and the eddies:

$$
g \iiint \frac{\overline{u^{\prime} \rho^{\prime}} \partial \bar{\rho} / \partial x+\overline{v^{\prime} \rho^{\prime}} \partial \bar{\rho} / \partial y}{d \tilde{\rho} / d z} d V
$$

and

$$
-\iiint\left(\overline{u^{\prime} u^{\prime}} \frac{\partial \bar{u}}{\partial x}+\overline{u^{\prime} v^{\prime}}\left(\frac{\partial \bar{v}}{\partial x}+\frac{\partial \bar{u}}{\partial y}\right)+\overline{v^{\prime} v^{\prime}} \frac{\partial \bar{v}}{\partial y}\right) d V
$$

where $\tilde{\rho}(z)$ is the reference state for potential density, here the horizontal average of the time mean. Because model field correlations are only available for potential temperature $\Theta$ and salinity $S$, a linear equation of density in the form $\rho=\rho_{0}(1+\beta S-\alpha \Theta)$, where $\alpha$ is the thermal and $\beta$ the haline expansion coefficient, has been used. The conversion from mean potential to eddy potential energy, term (2a), can be used as an indicator for baroclinic instability (BCI) (Beckmann et al. 1994; Böning and Budich 1992), the work of the Reynolds stresses on the shear, term (2b) if positive, for barotropic instability (BTI).

Figure 10 shows the $2^{\circ}$ running mean meridional dependence of the two conversion terms, averaged over the top $1100 \mathrm{~m}$ and three zonal bands: one intersecting the Agulhas retroflection area (Fig. 10a), one intersecting the source regions and the recirculation of the Agulhas Current (Fig. 10b), and one in the open Indian Ocean (Fig. 10c). Maxima of "potential" for BCI are found 

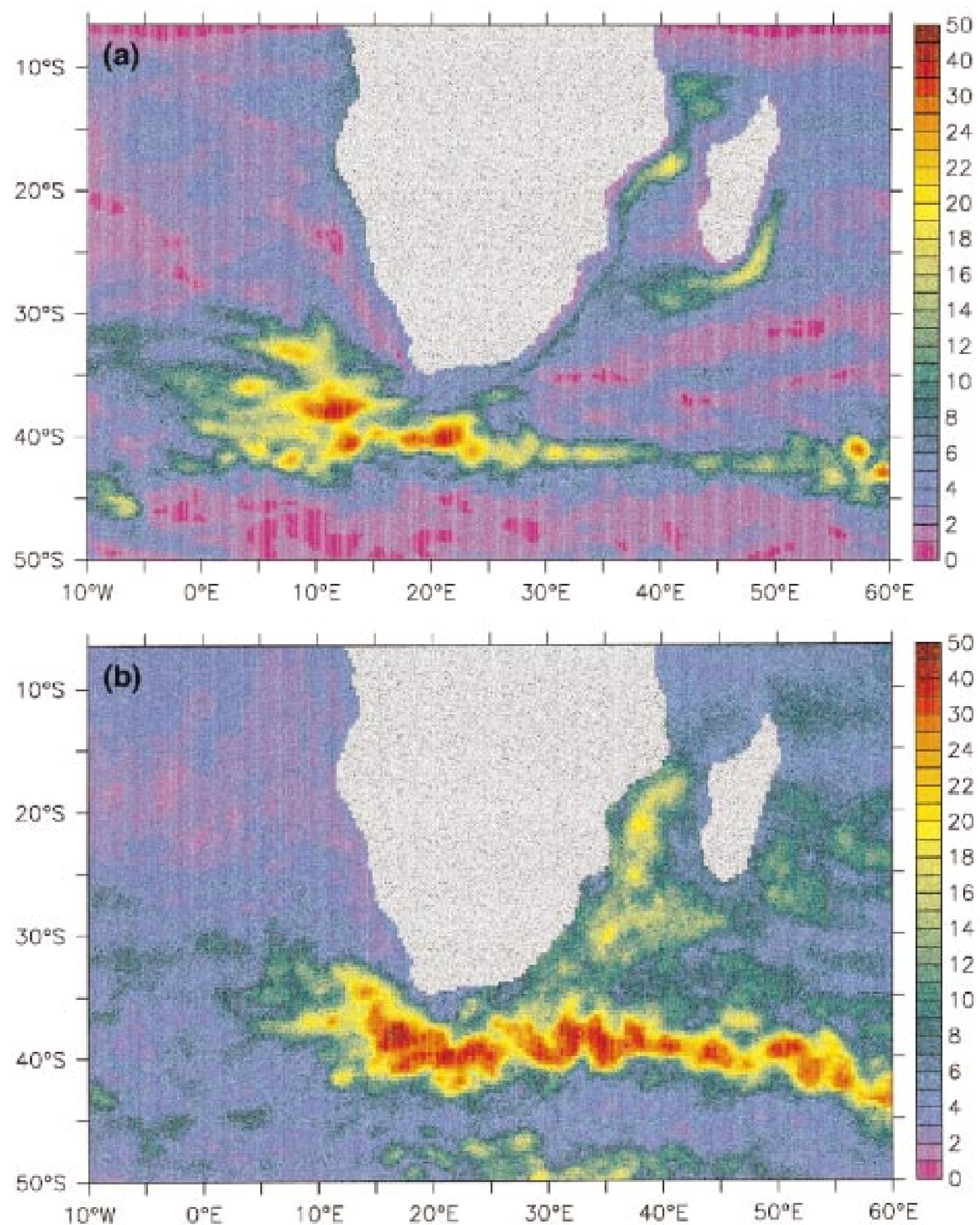

FIG. 8. Rms of the sea surface height anomaly for (a) the model, year 31; (b) the combination of TP/ERS-1, Nov 1992-Oct 1993. Units are $\mathrm{cm}$ (note the exaggerated color interval with steps of 1 in the range $0-25$ and 5 above). 


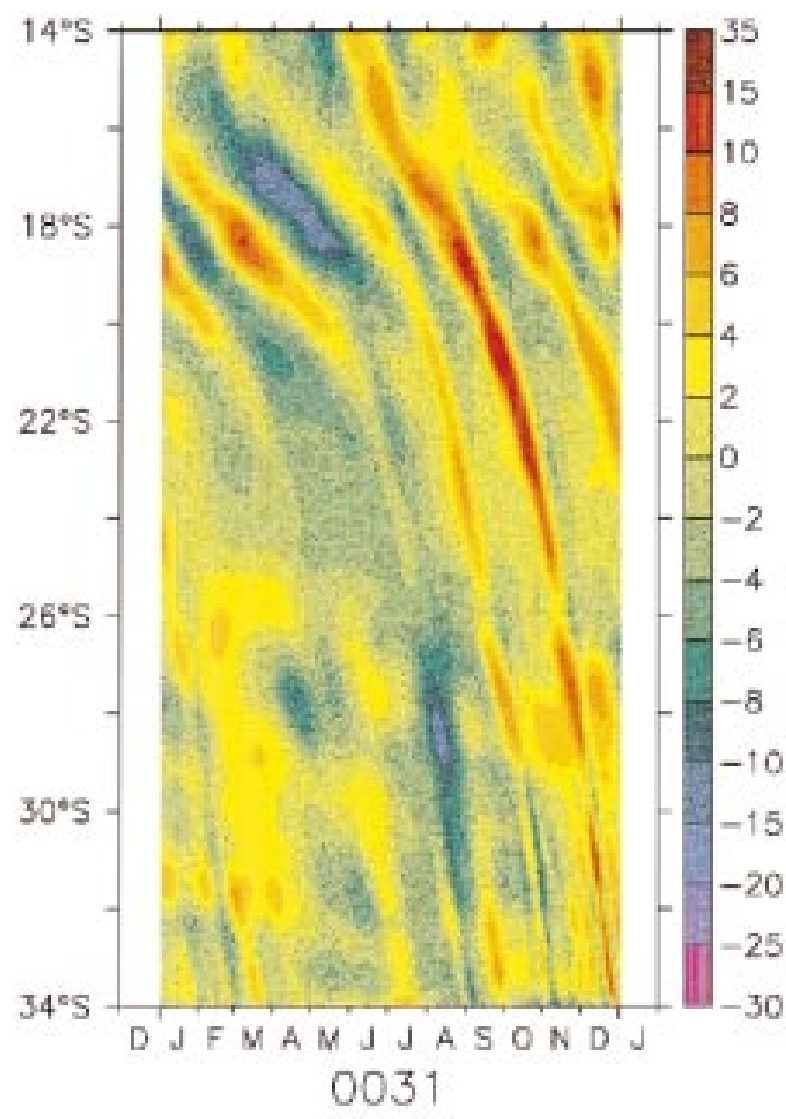

(a)

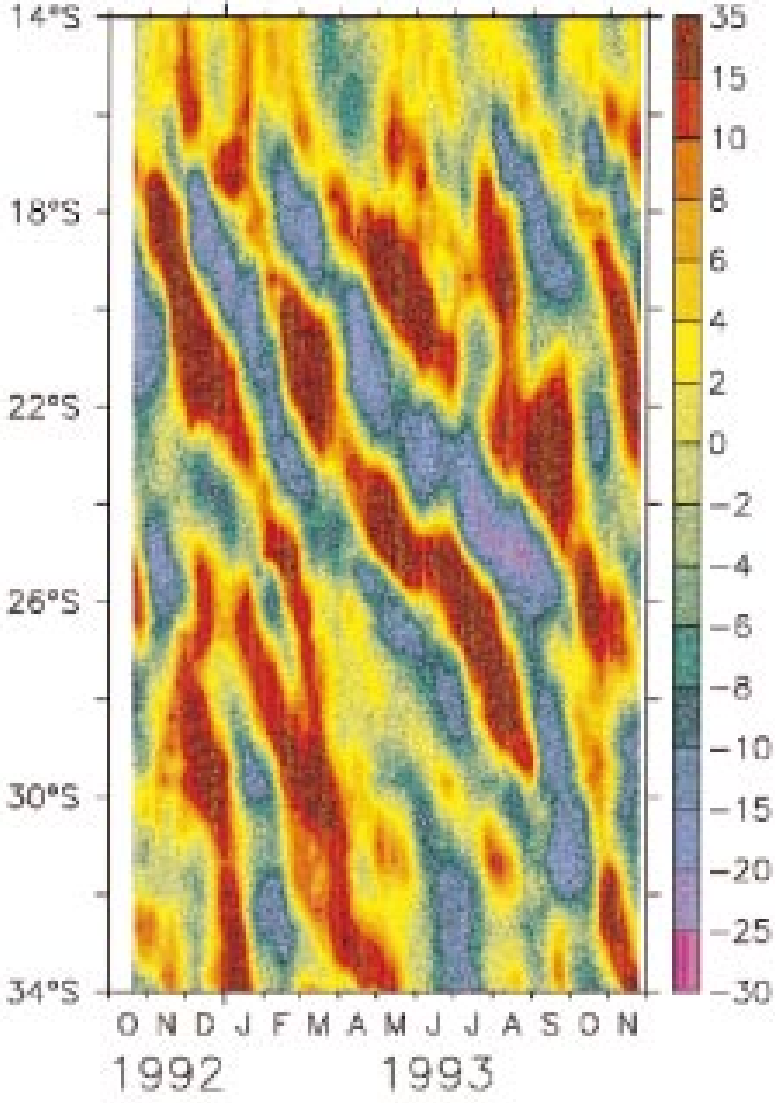

(b)

FIG. 9. Time series of sea surface anomalies, averaged over a $4^{\circ}$ wide strip along the African coast (in cm). (a) Anomalies of the diagnostic sea surface height, model year 31; (b) anomalies of the combined TP/ERS-1 satellite data (only points with a water depth greater than 1000 $\mathrm{m}$ are considered). Notice the irregular contour interval.

in the retroflection region of the Agulhas Current (around $40^{\circ} \mathrm{S}$ in Fig. 10a), along the Agulhas Return Current $\left(40^{\circ}-45^{\circ} \mathrm{S}\right.$ in Figs. $10 \mathrm{~b}$ and $\left.10 \mathrm{c}\right)$ and in the South Equatorial Current $\left(10^{\circ}-20^{\circ} \mathrm{S}\right.$ in Figs. $10 \mathrm{~b}$ and 10c).

The "potential" for BTI is generally lower and, except in the regions named above, is not significantly different from zero. Only in the northern part of the Mozambique Channel where the eddies are generated is the term for BTI bigger than those responsible for the BCI $\left(10^{\circ}-20^{\circ} \mathrm{S}\right.$ in Fig. 10b).

We therefore conclude that the generating mechanism of the Mozambique eddies is different from those of the Agulhas rings or the eddies generated along the Agulhas Return Current. Interesting to note is the pronounced minimum in term $2 b$ - an indicator for "negative BTI." This means that an energy transfer occurs from the eddies to the shear, so the eddies seem to maintain the mean flow. It is difficult to compare values between the different meridional profiles because of the strong dependence on the averaging region, but it seems clear that BTI plays an important role in the northern Mozambique Channel. The ability of generating Mozambique eddies does not depend on the wind field. The terms calculated for a model run with Hellerman and Rosenstein (1983) wind forcing, which is stronger than the ECMWF forcing, does not give significantly different results (here not shown).

\section{Discussion and summary}

It is difficult to verify the occurrence of the mesoscale eddies in the source regions of the Agulhas Current as seen in our model. Because of sparseness of hydrographic data in this region (first of all there are no longterm time series) an uncertainty exists about the circulation in the Mozambique Channel. Several authors gave pictures on a steady circulation in the Mozambique Channel that were inconsistent with one another. Harris (1972) found three anticyclonic vortices with diameters of $300 \mathrm{~km}$ transporting $10-20 \mathrm{~Sv}$. He noted that, if these features were nonstationary, as it seems from observations, they could be responsible for the time dependency of the water mass characteristics in the Agulhas Current. He also noted a strong anticyclonic eddy in the vicinity of Durban at $30^{\circ} \mathrm{S}$. Lutjeharms (1976) examined 

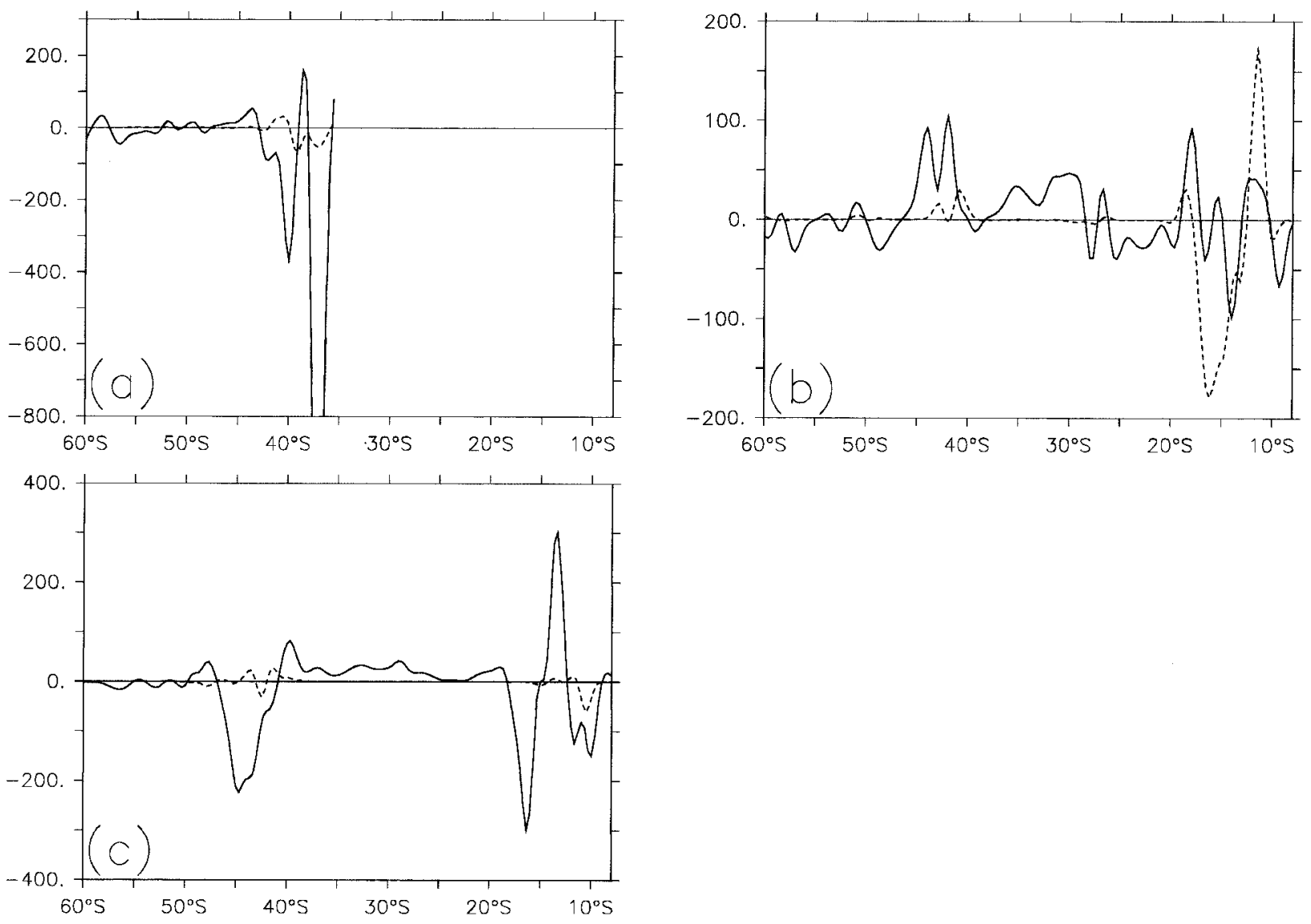

FIG. 10. Term $2 \mathrm{a}$ (solid) and $2 \mathrm{~b}$ (dashed) per unit volume: a $2^{\circ}$ running mean, averaged over the upper $1100-\mathrm{m}$ depth and over the longitudinal ranges of (a) $19^{\circ}-21^{\circ} \mathrm{E}$, (b) $41^{\circ}-43^{\circ} \mathrm{E}$, (c) $60^{\circ}-62^{\circ} \mathrm{E}$. Units are $10^{4} \mathrm{~cm}^{2} \mathrm{~s}^{-3}$.

data of the northeast monsoon season and found inflow in the Agulhas Current mainly in the upper layers whereby the intermediate layers are fed both through the channel and from east of Madagascar. The circulation that Sætre and Da Silva (1984) found in the Mozambique Channel was also dominated by anticyclonic vortices but these had different locations and sizes compared to the results of Harris (1972), which supports the theory of a nonpermanent circulation in the channel. At the latitude of Maputo $\left(26^{\circ} \mathrm{S}\right)$ they noticed an atypical $T-S$ distribution and interpreted this as a result of intensive mixing due to eddy formation. Gründlingh and Pearce (1984) went a step further and noted that discrepancies about the large-scale variability in the Agulhas Current could be explained by mesoscale eddies in the northern Agulhas Current, but they had in mind more the cyclonic vortices found in the northern Agulhas Current. Nevertheless the same argument can be used to support the existence of the anticyclonic eddies in the source regions of the Agulhas Current. Sætre (1985) examined the surface circulation of the Mozambique Channel from shipdrift data and found high velocities off the African coast at $14^{\circ} \mathrm{S}$ and $23^{\circ} \mathrm{S}$, which are comparable with the maxima at the same locations as in our model. Together with the fact that the circulation in the channel was clearly anticyclonic, he concluded a noncontinuous flow in the Mozambique Current. However, the large anticyclonic gyre in the northern part of the channel is well documented by Donguy and Piton (1991); farther south, in the narrows of the channel, they noted strong variability. To summarize, at this point the discrepancies in the hydrographic data can only be explained by a nonpermanent circulation and the occurrence of eddies in the Mozambique Channel.

The East Madagascar Current, on the other hand, is a well-defined flow. It runs southward along the east coast of Madagascar and retroflects at the southern tip (Lutjeharms et al. 1981). Similar to the circulation in Mozambique Channel, there is a time-dependent component in the current that results in short-time flow reversals (Schott et al. 1988). It has been speculated that additional southward flow and countercurrent structures in the measurements of Lutjeharms et al. (1981) at $23^{\circ} \mathrm{S}$ are due to the presence of mesoscale eddies (Swallow et al. 1988). Trajectories of surface drifters south of Madagascar and in the southern end of the Mozambique Channel show anticyclonic vortices (Lutjeharms et al. 1981). 
Single eddies have been tracked using satellite data during their drift from Mozambique Channel and from the eastern side of Madagascar (Gründlingh 1995). Their drift rates of about $7 \mathrm{~cm} \mathrm{~s}^{-1}$ are in good agreement with our model results, but the spins are mostly cyclonic. The consequence of this cyclonicity is an adherence of the eddies to the offshore edge of the Agulhas Current and not absorption. Some of the observed eddies in the southwestern Indian Ocean have anticyclonic spin (Gründlingh et al. 1991) like the eddies in our model but in those cases the drift directions are not in good agreement.

The best support for the theory of the drift of mesoscale eddies in the source regions of the Agulhas Current and the current itself comes from more statistical analyses of satellite data. Wang and Koblinsky (1996) found high variability in the TP data at $32^{\circ} \mathrm{S}$ and related this to local midocean topographic generation of baroclinic Rossby waves. In any case, anticyclonic structures have been found that travel-as in our modelsouthward. Stammer et al. (1996) examined TP data and found a picture of the variability in the Mozambique Channel similar to the one in our model and east of Madagascar. This is not surprising because of the same source data, but it is interesting to note that the POCM model also shows enhanced variability in the region. The same is true for the Parallel Ocean Program Model (POP: Maltrud et al. 1998), although both models do not reach the values of TP. Fu and Smith (1996) mentioned also a discrepancy of the TP and POP values in Mozambique Channel. Maltrud et al. noted that the variability is significantly increased when daily data are used for the surface forcing.

The periods around 50 days found in the interoceanic heat transport and the vorticity dynamics (Fig. 5) are noted also in the literature. Mysak and Mertz (1984) reported oscillations with periods between 40 and 60 days in the region northwest of Mozambique Channel $\left(2^{\circ}-4^{\circ} \mathrm{S}\right)$ and related them to local wind fluctuations. The same periods have been found in the SEC just north (Quadfasel and Swallow 1986) and east of Madagascar (Schott et al. 1988). In contrast to Mysak and Mertz (1984), Kindle and Thompson (1989) used a one-layer reduced-gravity model to relate the 50-day period to a barotropic instability of the system spanning the East Madagascar Current and the East African Coastal Current. This is supported by this model as the energy analyses in section 4 indicate. The same model of Kindle (1991) also showed enhanced variability in the Mozambique Channel, but more focused along the African Coast than seen in our model experiments. Nevertheless a connection to the Agulhas Current (respective to the southern boundary) exists. It is ambiguous how to compare the results of such one-layer models with our experiments and if the high variability that Kindle (1991) has shown is due to traveling isolated eddies. Finally, from a recent statistical analysis of TP data a period in the 60-day band indicates eddy shedding in Mozambique Channel (Stammer 1997).

The occurrence of the anticyclonic eddies in the source regions and the Agulhas Current itself does not contradict the theory and observations of the Natal Pulses (Lutjeharms and Roberts 1988). These soliton meanders are generated in the Natal Bight $\left(29^{\circ} \mathrm{S}\right)$ due to a barotropic instability and travel downstream with speeds between 15 (van Leeuwen et al. 1999) and $20 \mathrm{~km} \mathrm{day}^{-1}$ (Lutjeharms and Roberts 1988). Their cyclonic nature causes an offshore displacement of the Agulhas Current, whereas the anticyclonic eddies in our model cause a stabilizing enhancement of the current together with an offshore countercurrent. Since the resolution here is too coarse to resolve the bottom topography of the Natal Bight in detail, we do not see any of these meanders in our results. But uncertainty exists about the triggering mechanisms of the Natal pulses (De Ruijter et al. 1999b): the absorption of deep-sea eddies is one of the possible candidates for causing a barotropic instability that is required for the generation of Natal pulses. It might be possible that the anticyclonic eddies seen in the model can provide this instability. On the other hand, a coexistence also is imaginable. A time series sequence of sea surface height maps from satellite data shows alternating coherent cyclonic and anticyclonic vortices in the Agulhas Current (van Leeuwen et al. 1999). If the Natal pulses would have a great influence on ring shedding south of Africa, as supposed by Lutjeharms and de Ruijter (1996), and therefore on the interoceanic transport, this is also true for the eddies in our results. A model with finer resolution would be required to study in detail the interaction of anticyclonic eddies in the source regions of the Agulhas Current and cyclonic pulses in the current itself as well as their influence on the shedding of Agulhaus rings.

Another insight in the interplay of Natal pulses and eddies with Agulhas rings comes from a study of Pichevin et al. (1999). With a simple model of a retroflecting current they found that Natal pulses do not influence the production of Agulhas rings. On the other hand, transport pulses (that are acting as the eddies in our model) do; every transport pulse leads to the separation of an Agulhas ring. This cannot be checked in the current version of our model because most of the eddies do not reach the southern tip of Africa in their complete form.

Summarizing, there seems to be great evidence in the hydrographic data that the eddies that are found in the source regions of the Agulhas Current in our model and that are traveling toward the southern tip of Africa occur in the real ocean. The existence of these eddies explains a number of discrepancies in the hydrography and shortterm reversals. A stringent verification for the eddies in Mozambique Channel comes from the satellite altimetry data that show clearly structures of traveling coherent vortices. These structures are also found in independent analyses. The enhanced variability at the southeastern 
coast of Madagascar indeed is more unclear, the eddies in the real ocean seem to come from the central Indian Ocean. When the eddies become absorbed by the Agulhas Current, pulsating transport enhancement occurs. Although the horizontal resolution of the model is not fine enough to track all eddies toward the southern tip of Africa nor to study an interplay with the Natal pulses, the results point out clearly that the eddies have enormous influence on the interoceanic transfer of heat, salt, and vorticity.

Acknowledgments. Special thanks are given to Armin Köhl and Dr. Nils Rix, who produced the maps of the TOPEX/Poseidon and ERS- 1 satellite data. Thanks are also given to Dr. A. Semtner and Dr. R. Tokmakian (both Naval Postgraduate School, Monterey), who made available the model data of POCM. Thank you also to Dr. Rolf Käse and Dr. Rob Tyler, who checked the manuscript and gave a lot of fruitful hints.

This work has been supported by the Bundesministerium für Bildung, Wissenschaft, Forschung und Technologie through the German contribution to WOCE under Grant 03F0157A.

\section{REFERENCES}

AVISO, 1998: AVISO user handbook: Sea level anomalies. AVI-NT011-312-CN 3.1 ed., 24 pp. [Available from CNES, BPi 2002, 18 Ave. Edouard Belin, 31401 Toulouse, France.]

Barnier, B., L. Siefridt, and P. Marchesiello, 1995: Thermal forcing for a global ocean circulation model from a three-year climatology of ECMWF analyses. J. Mar. Syst., 6, 363-380.

Beckmann, A., C. W. Böning, B. Brügge, and D. Stammer, 1994: On the generation and role of eddy variability in the central North Atlantic Ocean. J. Geophys. Res., 99, 20 381-20 391.

Biastoch, A., 1998: Zirkulation und Dynamik in der Agulhasregion anhand eines numerischen Modells. Ph.D. thesis, Berichte aus dem Institut für Meereskunde, 301, Kiel, Germany, 118 pp. [Available from Dr. Arne Biastoch, Dept. of Theoretical Oceanography, Institut für Meereskunde, Düsternbrooker Weg 20, 24105 Kiel, Germany.]

Böning, C. W., and R. G. Budich, 1992: Eddy dynamics in a primitive equation model: Sensitivity to horizontal resolution and friction. J. Phys. Oceanogr., 22, 361-381.

Bowman, M. J., 1985: On the $\beta$-induced coastal trapping of a baroclinic eddy. J. Phys. Oceanogr., 15, 817-822.

Bretherton, F., R. Davies, and C. Fandry, 1976: A technique for objective analysis and design of oceanographic experiments applied to MODE-73. Deep-Sea Res., 23, 559-582.

Broecker, W. S., 1991: The great ocean conveyor. Oceanography, 4, 79-89.

Bryan, K., 1969: A numerical method for the study of the circulation of the World Ocean. J. Comput. Phys., 4, 347-376.

Byrne, D. A., A. L. Gordon, and W. F. Haxby, 1995: Agulhas eddies: A synoptic view using Geosat ERM data. J. Phys. Oceanogr., 25, 902-917.

Chelton, D. B., R. A. DeSzoeke, M. G. Schlax, K. E. Naggar, and N. Siwertz, 1998: Geographical variability of the first baroclinic Rossby radius of deformation. J. Phys. Oceanogr., 28, 433-460.

Cox, M. D., 1984: A primitive equation 3-dimensional model of the ocean. Tech. Rep. 1, GFDL Ocean Group, Princeton, NJ, 40 pp. [Available from GFDL, P.O. Box 308, Princeton, NJ 08542.]

De Ruijter, W. P. M., A. Biastoch, S. S. Drijfhout, J. R. E. Lutjeharms, R. Matano, T. Pichevin, P. J. van Leeuwen, and W. Weijer, 1999a:
Indian-Atlantic inter-ocean exchange: Dynamics, estimation and impact. J. Geophys. Res., in press.

_ , P. J. van Leeuwen, and J. R. E. Lutjeharms, 1999b: Generation and evolution of Natal pulses: Solitary meanders in the Agulhas Current. J. Phys. Oceanogr., in press.

Donguy, J.-R., and B. Piton, 1991: The Mozambique channel revisited. Oceanol. Acta, 14, 549-558.

Duncombe Rae, C. M., 1991: Agulhas retroflection rings in the South Atlantic Ocean: An overview. S. Afr. J. Mar. Sci., 11, 327-344.

Flierl, G. A., 1977: The application of linear quasigeostrophic dynamics to Gulf Stream rings. J. Phys. Oceanogr., 7, 365-379.

FRAM Group, 1991: An eddy-resolving model of the southern ocean. Eos, Trans. Amer. Geophys. Union, 72, 169-172.

Fu, L.-L., and R. D. Smith, 1996: Global ocean circulation from satellite altimetry and high-resolution computer simulation. Bull. Amer. Meteor. Soc., 77, 2625-2636.

Garzoli, S. L., A. L. Gordon, V. Kamenkovich, D. Pillsbury, and C. Duncombe-Rae, 1996: Variability and sources of the southeastern Atlantic circulation. J. Mar. Res., 54, 1039-1071.

Gordon, A. L., 1985: Indian-Atlantic transfer of thermocline water at the Agulhas retroflection. Science, 227, 1030-1033.

- , and W. F. Haxby, 1990: Agulhas Eddies invade the South Atlantic: Evidence from Geosat altimeter and shipboard conductivity-temperature-depth survey. J. Geophys. Res., 95, 31173125.

— , R. F. Weiss, W. M. Smethie, and M. J. Warner, 1992: Thermocline and intermediate water communication between the South Atlantic and Indian Oceans. J. Geophys. Res., 97, 72237240 .

—, S. Ma, D. B. Olson, P. Hacker, A. Ffield, L. D. Talley, D. Wilson, and M. Baringer, 1997: Advection and diffusion of Indonesian Throughflow water within the Indian Ocean South Equatorial Current. Geophys. Res. Lett., 24, 2573-2576.

Gründlingh, M. L., 1983: On the course of the Agulhas Current. S. Afr. Geogr. J., 65, 49-57.

- 1995: Tracking eddies in the southeast Atlantic and southwest Indian Oceans with TOPEX/Poseidon. J. Geophys. Res., 100, 24 977-24 986.

— , and A. F. Pearce, 1984: Large vortices in the northern Agulhas Current. Deep-Sea Res., 31, 1149-1156.

— , R. A. Carter, and R. C. Stanton, 1991: Circulation and water properties of the southwest Indian Ocean, spring 1987. Progress in Oceanography, Vol. 28, Pergamon, 305-342.

Han, Y.-J., 1984: A numerical World Ocean general circulation model. Part II: A baroclinic experiment. Dyn. Atmos. Oceans, 8, 141172.

Haney, R. L., 1971: Surface thermal boundary condition for ocean circulation models. J. Phys. Oceanogr., 1, 241-248.

Harris, T. F. W., 1972: Sources of the Agulhas Current in the spring of 1964. Deep-Sea Res., 19, 633-650.

Hellerman, S., and M. Rosenstein, 1983: Normal monthly wind stress over the world ocean with error estimates. J. Phys. Oceanogr., 13, 1093-1104.

Kindle, J. C., 1991: Topographic effects on the seasonal circulation of the Indian Ocean. J. Geophys. Res., 96, 16 827-16 837.

—, and J. D. Thompson, 1989: The 26- and 50-day oscillations in the western Indian Ocean: Model results. J. Geophys. Res., 94, 4721-4736.

Kraus, E. B., and J. S. Turner, 1967: A one-dimensional model of the seasonal thermocline. II: The general theory and its consequences. Tellus, 19, 98-105.

Le Traon, P. Y., and F. Ogor, 1998: ERS-1 orbit improvement using TOPEX/Poseidon: The $2 \mathrm{~cm}$ challenge. J. Geophys. Res., 103, 8045-8058.

_- P. Gaspar, F. Bouyssel, and H. Makhmara, 1995: Using TOPEX/ Poseidon data to enhance ERS-1 orbit. J. Atmos. Oceanic Technol., 12, 161-170.

Levitus, S., and T. P. Boyer, 1994: Temperature. Vol. 4, World Ocean Atlas 1994, NOAA Atlas NESDIS, $117 \mathrm{pp}$. 
R. Burgett, and T. P. Boyer, 1994: Salinity. Vol. 3, World Ocean Atlas 1994, NOAA Atlas NESDIS, 99 pp.

Lutjeharms, J. R. E., 1976: The Agulhas Current System during the northeast monsoon season. J. Phys. Oceanogr., 6, 665-670.

— 1996: The exchange of water between the South Indian and South Atlantic Oceans: A review. The South Atlantic Present and Past Circulation, G. Wefer, Ed., Elsevier, 125-162.

- , and H. R. Roberts, 1988: The Natal pulse: An extreme transient on the Agulhas Current. J. Geophys. Res., 93, 631-645.

- and R. C. van Ballegooyen, 1988: The retroflection of the Agulhas Current. J. Phys. Oceanogr., 18, 1570-1583.

- , and D. J. Webb, 1995: Modelling the Agulhas Current system with FRAM (Fine Resolution Antarctic Model). Deep-Sea Res., 42, 523-551.

_ and W. P. M. de Ruijter, 1996: The influence of the Agulhas Current on the adjacent coastal ocean: Possible impacts of climate change. J. Mar. Syst., 7, 321-336.

- , N. D. Bang, and C. P. Duncan, 1981: Characteristics of the currents east and south of Madagascar. Deep-Sea Res., 28, 879 899.

Maltrud, M. E., R. D. Smith, A. J. Semtner, and R. C. Malone, 1997: Global eddy-resolving ocean simulations driven by 1985-1994 atmospheric winds. J. Geophys. Res., 103, 30 825-30 853.

Matano, R. P., 1996: A numerical study of the Agulhas Retroflection: The role of bottom topography. J. Phys. Oceanogr., 26, 22672279 .

McClean, L. L., A. J. Semtner, and V. Zlotnicki, 1997: Comparisons of mesoscale variability in the Semtner-Chervin $1 / 4{ }^{\circ}$ model, the Los Alamos Parallel Ocean Program $1 / 6^{\circ}$ model, and TOPEX/ Poseidon data. J. Geophys. Res., 102, 25 203-25 226.

Mysak, L. A., and G. J. Mertz, 1984: A 40- to 60-day oscillation in the source region of the Somali Current during 1976. J. Geophys. Res., 89, 711-715.

Nof, D., 1988: Eddy-wall interactions. J. Mar. Res., 46, 527-555.

Pacanowski, R. C., 1996: MOM 2 version 2, documentation, user's guide and reference manual. Tech. Rep. 3.2, GFDL, 329 pp. [Available from GFDL, P.O. Box 308, Princeton, NJ 08542.]

Pearce, A. F., and M. L. Gründlingh, 1982: Is there a seasonal variation in the Agulhas Current? J. Mar. Res., 40, 177-184.

Pichevin, T., D. Nof, and J. R. E. Lutjeharms, 1999: Why are there Agulhas rings? J. Phys. Oceanogr., 29, 693-707.

Quadfasel, D. R., and J. C. Swallow, 1986: Evidence for 50-day period planetary waves in the South Equatorial Current of the Indian Ocean. Deep-Sea Res., 33, 1307-1312.

Ribbe, J., and M. Tomczak, 1997: Effect of the missing Indonesian inflow in the Fine Resolution Antarctic Model. J. Phys. Oceanogr., 27, 445-455.

Sætre, R., 1985: Surface currents in the Mozambique Channel. DeepSea Res., 32, 1457-1467.

_ , and A. J. Da Silva, 1984: The circulation of the Mozambique Channel. Deep-Sea Res., 31, 485-508.

Schott, F., M. Fieux, J. Kindle, J. Swallow, and R. Zantopp, 1988: The boundary currents east and north of Madagascar. 2. Direct measurements and model comparisons. J. Geophys. Res., 93, 4963-4974.

Semtner, A. J., and R. M. Chervin, 1992: Ocean general circulation from a global eddy-resolving model. J. Geophys. Res., 97, 54935550 .

Shapiro, R., 1970: Smoothing, filtering, and boundary effects. Rev. Geophys., 8, 359-387.

Shi, C., and D. Nof, 1994: The destruction of lenses and generation of wodons. J. Phys. Oceanogr., 24, 1120-1136.

Stammer, D., 1997: Global characteristics of ocean variability estimated from regional TOPEX/Poseidon altimeter measurements. J. Phys. Oceanogr., 27, 1743-1769.

_ , R. Tokmakian, A. Semtner, and C. Wunsch, 1996: How well does a $14^{\circ}$ global circulation model simulate large-scale oceanic observations? J. Geophys. Res., 101, 25 779-25 811.

Stevens, D. P., 1990: On open boundary conditions for three dimensional primitive equation ocean circulation models. Geophys. Astrophys. Fluid Dyn., 51, 103-133.

Stramma, L., and J. R. E. Lutjeharms, 1997: The flow field of the subtropical gyre of the south Indian Ocean. J. Geophys. Res., 102, 5513-5530.

Swallow, J., M. Fieux, and F. Schott, 1988: The boundary currents east and north of Madagascar. 1. Geostrophic currents and transports. J. Geophys. Res., 93, 4951-4962.

Thompson, S. R., 1995: Sills of the global ocean: a compilation. Ocean Modelling (unpublished manuscripts), 109, 7-9.

— D. P. Stevens, and K. Döös, 1997: The importance of interocean exchange south of Africa in a numerical model. J. Geophys. Res., 102, 3303-3315.

van Ballegooyen, R. C., M. L. Gründlingh, and J. R. E. Lutjeharms, 1994: Eddy fluxes of heat and salt from the southwest Indian Ocean into the southeast Atlantic Ocean: A case study. J. Geophys. Res., 99, 14 053-14070.

van Leeuwen, P. J., W. P. M. de Ruitjer, and J. R. E. Lutjeharms, 1999: Natal pulses and the formation of Agulhas rings. J. Geophys. Res., in press.

Wang, L., and C. J. Koblinsky, 1996: Low-frequency variablity in the region of the Agulhas Retroflection. J. Geophys. Res., 101, 3597-3614. 